\title{
A EVOLUÇÃO DO MERCADO DE CACHAÇA ARTESANAL
}

\section{THE EVOLUTION OF THE ARTISANAL CACHAÇA MARKET}

\author{
Paola de Andrade Gonçalves - paola.goncalves51@gmail.com \\ Faculdade de Tecnologia de Taquaritinga - Taquaritinga - São Paulo - Brasil \\ Fabio Alexandre Cavichioli - fabio.cavichioli@fatectq.edu.br \\ Faculdade de Tecnologia de Taquaritinga - Taquaritinga - São Paulo - Brasil
}

DOI: 10.31510/infa.v18i1.1132

Data de submissão: 16/04/2021

Data do aceite: 09/07/2021

Data da publicação: 30/07/2021

\begin{abstract}
RESUMO
Descrita em alguns relatos do século XVI como uma espécie de "vinho de cana", somente consumida por escravos e nativos, ainda desconhecida, chegava ao Brasil a cachaça. Entretanto, na medida em que a popularização da bebida se dava, os colonizadores começaram a substituir as caras bebidas importados da Europa pelo consumo desta mais acessível. Esta típica bebida tem um grande valor histórico no Brasil e ganhou espaço ao longo dos anos. O objetivo deste trabalho é desmistificar a cachaça e mostrar a evolução da cachaça artesanal no mercado mundial, pois ela está presente na história do país, desde os tempos da colonização, e são inúmeras as versões para o aparecimento desta bebida destilada. Tornou-se a segunda mais consumida entre os brasileiros, perdendo somente para a cerveja, e também recebendo reconhecimento e valor fora do país, com grande ascensão na exportação. Este trabalho foi desenvolvido por meio de pesquisa bibliográfica, com base em obras que abordam o tema escolhido; foram feitas pesquisas focadas em referências teóricas já analisadas e publicadas, por meio de sites oficiais, revistas online, reportagens e artigos científicos.
\end{abstract}

Palavras-chave: Destilado. Cana de açúcar. Bebida histórica. Análise do setor.

\begin{abstract}
Described in some reports from the 16th century as a kind of "cane wine", consumed only by slaves and indigenous people, still unknown, arrived in Brazil the cachaça. However, as the drink became more popular, the colonizers began to replace expensive drinks imported from Europe with the consumption of this more affordable one. This typical drink has great historical value in Brazil and has been gaining space over the years. The objective of this work is to demystify cachaça and show the evolution of artisanal cachaça in the world market, because it has been present in the history of the country, since the times of colonization, and there are countless versions for the appearance of this distilled drink. This work was developed by means of bibliographic research, based on works that approach the chosen theme; researches were carried out with a focus on theoretical references already analyzed and published, through official websites, online magazines, reports and scientific articles.
\end{abstract}


Keywords: Distillate. Sugar cane. Historic drink. Sector analysis.

\section{INTRODUÇÃO}

A cachaça, bebida feita da fermentação e destilação do melaço proveniente da canade-açúcar foi descoberta pelos escravos dos engenhos de açúcar em meados do século XVI.(EMPRAPA,2007)

Segundo o Site da Cachaça (2015), no processo de fabricação do açúcar, os escravos realizavam a colheita da cana, e após a separação, passava por um processo de esmagamento dos caules, para que fossem levadas ao fogo em grandes tachos, se transformando em um melaço. Nesse processo de cozimento, era fabricado um caldo mais grosso, chamado de "cagaça", que era servido aos escravos, e servido junto com as sobras da cana para os animais. Tal hábito fazia com que a cagaça fermentasse com a ação do tempo e do clima, produzindo um líquido de alto teor alcoólico.

Inicialmente, a cachaça aparecia descrita em alguns relatos do século XVI como uma espécie de "vinho de cana", somente consumida pelos escravos e nativos. Entretanto, na medida em que a popularização da bebida se dava, os colonizadores começaram a substituir as caras bebidas importados da Europa, como vinhos e a bagaceira (aguardente de bagaço de uva), pelo consumo da popular e acessível cachaça.

Tornou-se símbolo de resistência da cultura brasileira e dos ideais inconfidentes, sendo um dos motivos dos altos números de Engenho no estado de Minas Gerais.

"Aguardente de cana, Caninha ou cachaça", é a bebida com graduação de 38 a 54\% em volume a $20{ }^{\circ} \mathrm{C}$, obtida do destilado alcoólico simples de cana-de-açúcar ou, ainda, pela destilação do mosto fermentado de cana-de-açúcar. (EMBRAPA, 2007)

Para se obter uma cachaça de qualidade algumas características são de suma importância no plantio da cana, como: maturação, teor de sacarose, fertilidade de solo, boa brotação, bom perfilhamento, resistência a doenças, ausência de florescimento, ausência de joção e fácil despalha.

A cachaça tem um papel fundamental na economia do Brasil, produtos de alta qualidade com altos valores que podem ser agregados constantemente sem abrir mão da sustentabilidade e da competitividade. Sua cadeia de produção movimenta bilhões em fornecimento de insumos, produção e comercialização. 
Dados oficiais da EMPRAPA estimam que a produção real seja próxima de 1,3 bilhões de litros por ano. A cachaça é a segunda bebida alcoólica mais consumida no Brasil.

As ações de publicidade estão cada vez mais mudando a maneira como as pessoas enxergam a bebida, e aumentando consequentemente o público consumidor da cachaça, sendo capaz de atingir diferentes faixas etárias e classes sociais. Outro fator positivo para o crescimento do mercado da cachaça foi o reconhecimento dos Estados Unidos, em abril de 2011, da cachaça como uma bebida oficialmente brasileira. Este reconhecimento faz com que toda cachaça que entrar em território estadunidense, tenha que ter sido produzida no Brasil, de acordo com os critérios locais de produção e qualidade. Este fato deve aumentar significativamente a exportação de cachaça no Brasil. (BEBIDA EXPRESS, 2013).

Por tanto, tendo em vista todas estas tendências, o futuro para essa tradicional bebida brasileira é grandioso. O objetivo do trabalho é mostrar como o mercado desta bebida evoluiu, se tornando a segunda mais consumida entre os brasileiros, perdendo somente para a cerveja, e recebendo reconhecimento e valor fora do país com grande ascensão na exportação.

\section{FUNDAMENTAÇÃO TEÓRICA}

A cachaça está presente na história do país, desde os tempos da colonização, e são inúmeras as versões para o aparecimento dessa bebida destilada, originalmente brasileira. Uma delas relata que, por volta de 1532, os portugueses teriam trazido à cana-de-açúcar e as técnicas de destilação da ilha da madeira e aprimorado por aqui, outra remete a um período posterior, onde os escravos que trabalhava em um engenho, no Estado de Pernambuco, armazenavam a "cagaça", um caldo esverdeado e escuro que se forma durante a fervura do caldo de cana. O líquido fermentava naturalmente e, por causa das alterações de temperatura, evaporava e condensava, formando pequenos pingos de cachaça nos tetos do engenho. (A LAVOURA, 2016).

Segundo Silva (2016), a produção em maior escala no Brasil começou nos fins do Século XVI, no período das Capitanias Hereditárias, conforme Gabriel Soares: "na altura de 1584 existiam oito casas de cozer méis na Bahia”. Há registros de que em 1610 a bebida já existia no Brasil, pois, durante a sua estadia em Salvador nessa época, o francês Pyrard de Laval escrevera: "Faz-se vinho com o suco da cana, que é barato, mas só para os escravos e filhos da terra".

Com o passar do tempo, a cachaça foi conquistando grande espaço na sociedade, em diversos níveis e classes sociais, tendo um papel importante no período pré-independência. 
Em fevereiro de 1922, durante a Semana de Arte Moderna, que, através dos campos literários e das artes plásticas, buscava romper as tradições acadêmicas e reforçar o acento brasileiro, principalmente nos Estados do Rio de Janeiro, São Paulo, Minas Gerais e Pernambuco, a cachaça volta à mesa, acompanhando pratos tradicionalmente brasileiros. (SILVA,2016).

\subsection{Análises De Mercado}

Quando se estuda objetivamente a cachaça, já se comprova que o atual perfil de seus consumidores deixou de vinculá-la à ideia de bebida desvalorizada e de baixa qualidade, comparando-a a destilados nobres como uísque e vodca. A cachaça hoje é a segunda bebida mais consumida no mercado interno, perdendo apenas para a cerveja (gráfico 1). (SEBRAE, 2015)

Gráfico 1: Consumo de bebidas alcoólicas no Brasil

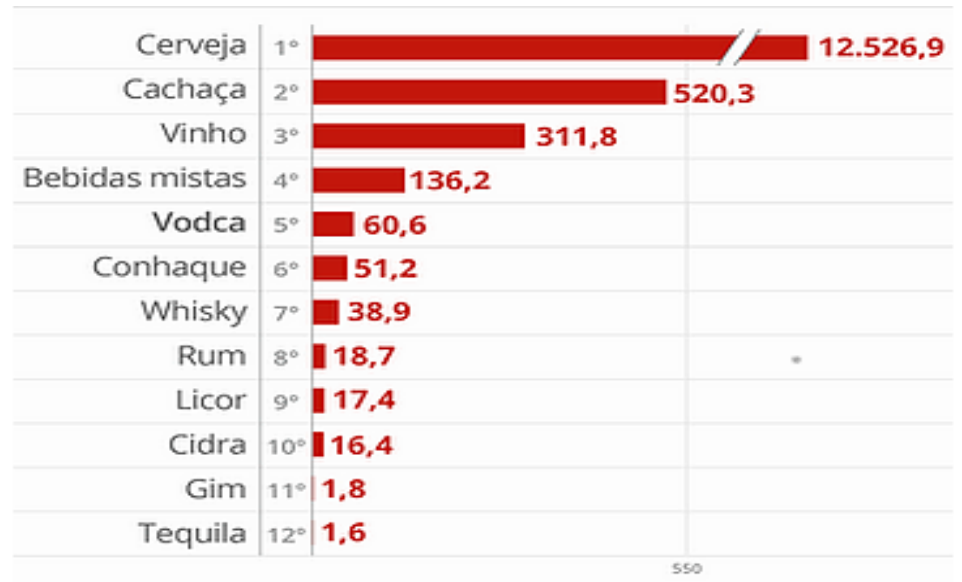

Fonte: EUROMONITOR,2018; DOMANI (2020)

Segundo o IBRAC (INSTITUTO BRASILEIRO DA CACHAÇA), estima-se que o Brasil possui capacidade instalada de produção de Cachaça de aproximadamente 1,3 bilhão de litros anuais, porém se produz anualmente menos de 800 milhões de litros. E segundo o último censo do IBGE de 2016, são 11.023 estabelecimentos produtores no País, sendo que, os principais produtores no país são: São Paulo, Pernambuco, Ceará, Minas Gerais e Paraíba.

A cachaça é reconhecida mundialmente como brasileira, e pode ser uma grande aposta no setor de destilados, existem diversos mercados potenciais a serem explorados, mas também há barreiras que devem ser transformadas em oportunidades, como os padrões de certificação, 
rigidez nas ações de controle sanitário e fitossanitário, tendo assim condições de manter uma forte competitividade no mercado internacional, que exige qualidade e impõe barreiras.

A cachaça vem ganhando espaço graças à certificação que é concedida pelo INSTITUTO NACIONAL DE METROLOGIA, NORMALIZAÇÃO E QUALIDADE INDUSTRIAL (INMETRO). O selo para a cachaça é o REGULAMENTO DE CONFORMIDADE DA CACHAÇA (RACC). (SEBRAE, 2015)

Segundo o site Bebida Express (2013), a Alemanha vem sendo e é um ótimo mercado consumidor, pois o consumo de destilados na região é bem expressivo e atinge uma média de 5,8 litros por pessoa a cada ano, isto porque a cachaça é conhecida principalmente como ingrediente para caipirinha, bebida que após os anos 90 passou a ser a bebida da moda na Europa.

\subsubsection{Concorrentes}

Segundo o site SEBRAE (2015), conhecer e analisar a concorrência são ações importantes para o mundo dos negócios. Preço, qualidade e diferentes formas de disponibilizar o produto e atender ao cliente destacam-se nesse cenário competitivo.

Para Michael Porter, a Vantagem Competitiva advém do valor que a empresa cria para seus clientes em oposição ao custo que tem para criá-la, portanto a formulação de uma estratégia competitiva é essencial para a empresa, pois esta dificilmente poder criar condições, ao mesmo tempo, para responder a todas as necessidades de todos os segmentos de mercado atendido. (EGESTOR, 2017).

A partir de inúmeras pesquisas, o setor da Cachaça artesanal se encontra altamente competitivo, devido a grande demanda e variedade que estamos encontrando no mercado. $\mathrm{O}$ que deve fazer seu diferencial e torna-la ainda mais bem sucedida é levar em consideração alguns requisitos, tais como: a embalagem, o rótulo, sua logomarca e principalmente o marketing, que faz todo o seu diferencial.

\subsubsection{Clientes}

Baseados em análises de diversos sites, notícias, e redes de comunicação, os clientes para uma cachaça de fabricação artesanal, são pessoas com um maior poder aquisitivo, que são amantes pela degustação da mesma, ou seja, pessoas que estão dispostas a pagar pela qualidade oferecida. 
Tendo em vista o grande aumente em exportação, a cachaça brasileira já vem sendo almejada fora do país e as condições atuais da economia atraem as empresas para o mercado exportador.

A análise SWOT ou FOFA é um método de planejamento estratégico que engloba a análise de cenários para a tomada de decisões. (IMME,2019). É de extrema importância no planejamento estratégico das organizações, com ela é possível obter a melhora no desempenho na tomada de decisões, principalmente se tratando do alcance de novos clientes e exploração de mercado.

Para a fabricação de cachaça artesanal pode-se observar alguns pontos da análise SWOT, tendo como base inúmeras pesquisas:

\section{Pontos Fortes}

- Produção limpa e grande controle de qualidade;

- Boa imagem fora do Brasil;

- Matéria prima em abundância na região brasileira;

\section{Pontos Fracos}

- Muita informalidade no setor;

- Público específico para o consumo;

- Elevada carga tributária;

\section{Oportunidades}

- Produto reconhecido como brasileiro (usar o nome do país para ganhar mercado estrangeiro);

- Tendência de consumo de produtos "Premium",

\section{Ameaças}

- Modismo de outros destilados;

- Drinques com outros destilados;

- Campanhas crescentes contra o consumo de bebidas.

\subsubsection{Consumidores}

Segundo o Programa Brasileiro de Desenvolvimento da Aguardente de Cana, Caninha ou Cachaça (PBDAC), a produção é em torno de 1,3 bilhão de litros por ano, sendo que cerca de $80 \%$ desse total é proveniente da fabricação industrial e $25 \%$, da forma artesanal. (EMBRAPA, 2007). 
O Brasil sendo um dos principais produtores, também é o maior consumidor, consome quase toda a produção de cachaça. Por volta de $1 \%$ a $2 \%$, apenas, é exportado para outros países, (gráfico 2).

Segundo o Jornal Estado de Minas, a "maior parte (80\%) da exportação correspondeu à cachaça industrial, sendo que a artesanal, produto de maior valor agregado decorrente de seu maior gasto em produção, representou somente $20 \%$ do volume total. Embora um quarto da produção vá para o Paraguai $(24,86 \%)$, a quantidade exportada aos países europeus com maior representatividade nas vendas corresponde a $44 \%$ do total. A Alemanha foi a destino de $23,3 \%$ desse montante." Em seguida, outros destinos são países como, Portugal, Itália, Espanha e Estados Unidos. (DOMANI,2020).

Gráfico 2: Principais países de destino em volume-2018
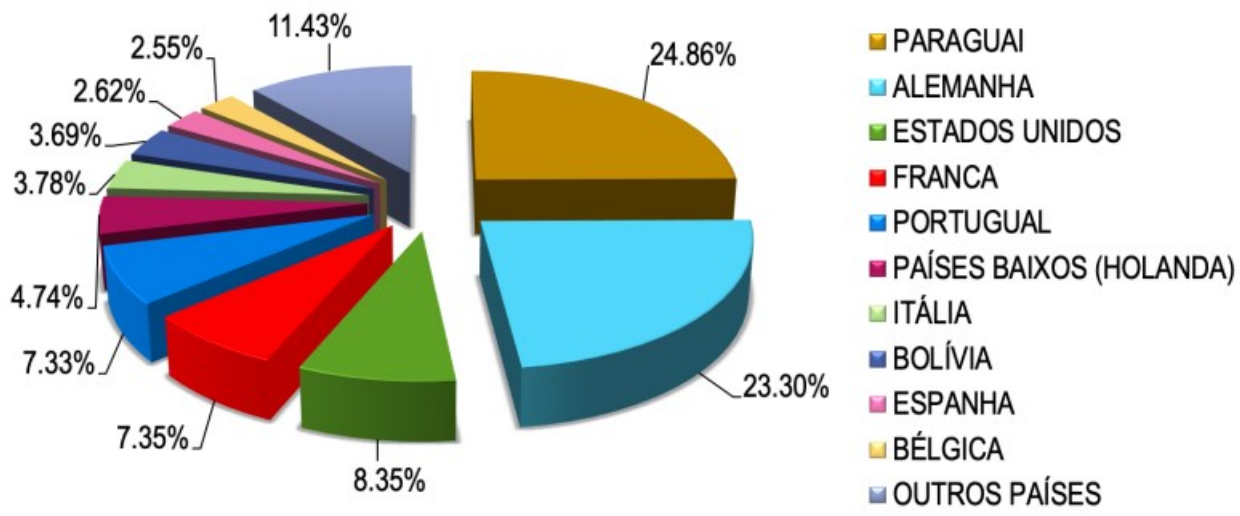

Fonte: Comex Start | Ministério da Economia (2018)

Segundo levantamentos no IBRAC, a cachaça é o primeiro destilado das Américas, tendo surgido antes do Pisco (aguardente de uva), da Tequila, do Rum e do Bourbon.

Portanto, a fim de aumentar o sucesso internacional da bebida, as certificações são essenciais para agregar valor ao produto, visto que passam segurança e qualidade sobre todo o processo de produção, passando também confiabilidade aos consumidores estrangeiros.

\subsubsection{Fornecedores}

O principal insumo utilizado na produção da cachaça artesanal é a cana de açúcar, produto este que temos em abundância no Brasil. De acordo com a Conab (Companhia 
Nacional de Abastecimento), foi divulgado em março de 2020, que o Brasil deve produzir 642,7 mil toneladas de cana-de-açúcar na safra 2019/2020. Resultado que representa um crescimento de 3,6\% em relação à safra anterior. (AGROPÓS,2020)

Devemos ter em mente que um fornecedor não é apenas aquele que faz a matéria prima, mas sim aquele que fará todo o diferencial no resultado final, pois é ele quem começara todo o processo. Segundo o SEBRAE (2014), o serviço do fornecedor influenciará diretamente no seu, pois a responsabilidade do prazo de entrega dele impactará diretamente no seu controle de estoque e produção e, também, no seu prazo de entrega.

Portanto, no momento de escolher um fornecedor, deve-se levar em consideração inúmeros fatores, tais como:

- Qualidade;

- Distância do fornecedor;

- Prazo de entrega.

- Confiabilidade;

- Preço.

Os itens citados acima são apenas alguns, pode se dizer que os mais importantes, pois a escolha correta de um fornecedor fará toda diferença em cada ciclo da operação efetuada.

\section{PROCEDIMENTOS METODOLÓGICOS}

Este trabalho foi desenvolvido por meio de pesquisa bibliográfica, com base em obras que abordam o tema escolhido: A evolução do mercado da cachaça artesanal. Foram feitas pesquisas focadas em referências teóricas já analisadas e publicadas, por meio de sites oficiais, revistas online, reportagens e artigos científicos.

\section{RESULTADOS E DISCUSSÃO}

Segundo Arthur (2021 apud LIMA, 2021), a cachaça transmite rica herança cultural do Brasil, e a diversidade dela se da devido ao fato de que ela é produzida em todo país. De acordo com Arthur (2021), os produtores de cachaça variam desde pequenas destilarias a empresas multinacionais.

De acordo com Salati (2021), o IBRAC assinou no final de 2020 um convênio com a Agência Brasileira de Promoção de Exportações e Investimentos (Apex-Brasil) que prevê investimentos no valor de R\$3,4 milhões no setor, até 2022. 
O mercado da cachaça se encontra em ascensão, dentro e fora do país, devido ao convênio citado acima, as expectativas e o objetivo é ampliar o número de exportações de cachaça. No site oficial do IBRAC, encontramos o seguinte relato: "O novo projeto prevê investimentos na ordem de $\mathrm{R} \$ 3$ milhões e tem como meta a participação de 55 empresas, entre micro, pequenas, médias e grandes empresas.”.

Ainda segundo o IBRAC, o novo projeto aprovado para o biênio 2020/2022 terá como mercados prioritários os seguintes países: Alemanha, França, México, Reino Unido, Suíça, Itália, Chile, Estados Unidos e Bélgica.

\subsection{Exportação Brasileira de cachaça}

Segundo Salati (2021), as exportações brasileiras de cachaça caíram em 2020 em função das dificuldades econômicas provocadas pela pandemia do coronavírus, afirma o Instituto Brasileiro da Cachaça (Ibrac).

De acordo com Arthur (2021), os principais mercados para exportação da cachaça são: EUA, Alemanha, França, Paraguai, Portugal e Itália, (figura 1).

Figura 1: Representação das exportações

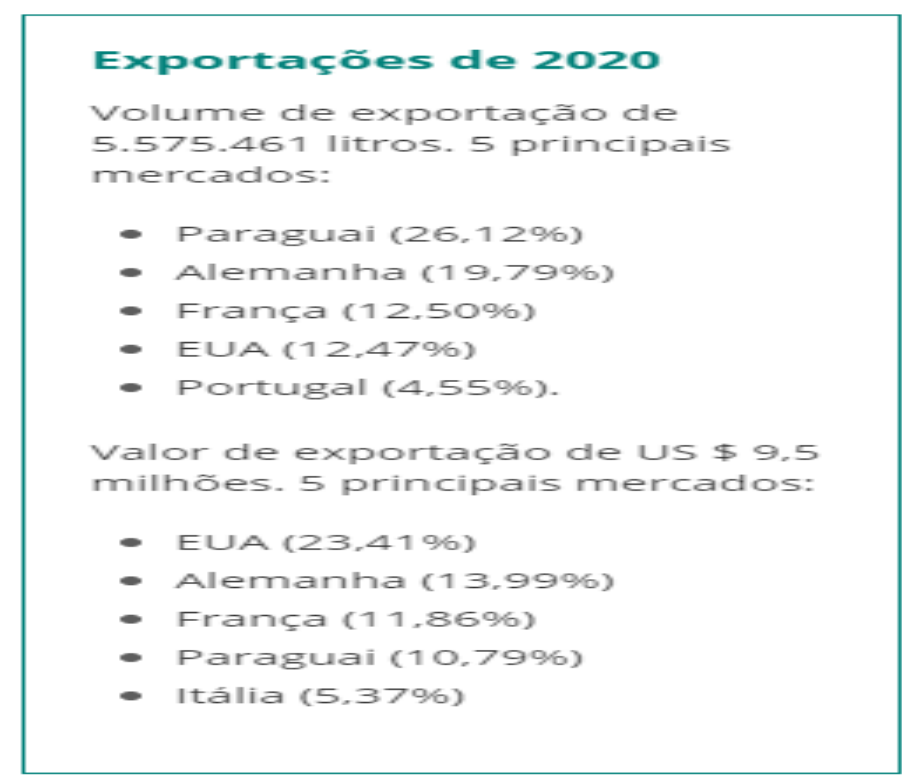

Fonte: ARTHUR, 2021; BEVERAGEDAILY (2021) 
Pode-se dizer, com base nas pesquisas e no quadro acima, que mesmo enfrentando uma pandemia mundial (COVID-19), e com queda geral nas exportações, ainda há alguns países que mantiveram seus números em alta.

\section{CONCLUSÃO}

Com base nos estudos levantados, pode-se considerar o mercado da Cachaça artesanal altamente promissor. Uma bebida com valor histórico, que foi passado ao longo de gerações, com riqueza em cada detalhe contado e descoberto.

Podemos classificar algumas vantagens concluídas ao longo deste trabalho, como uma delas sendo o Brasil um dos países mais ricos em sua matéria prima, a cana de açúcar, devido à grande adaptabilidade da cana em nosso clima e solo, a conquista histórica da cachaça sendo reconhecida como genuinamente brasileira, fazendo com que as portas para o mercado exterior se abrissem e entrasse em ascensão.

Assim como existem pontos positivos, há também os pontos negativos, por exemplo, a cachaça fabricada artesanalmente requer muito mais tempo, qualidade apurada da matéria prima, e produtos de alta qualidade acabam agregando custos maiores, sem deixar de citar também a grande concorrência com outros destilados.

Portanto, podemos concluir que o mercado da cachaça artesanal evoluiu positivamente. Além de grande produção interna, ganhou grande reconhecimento no mercado exterior.

\section{REFERÊNCIAS}

ALMEIDA, C.; Resíduos do alambique. 2015. Disponível em: $<$ http://www.sitedacachaca.com.br/residuos-do-alambique/> Acesso em: 04 de outubro de 2020 .

ARTHUR, $R$. Cachaça is far more than the caipirinha!. 2021. Disponível em $<$ https https://www.beveragedaily.com/Article/2021/03/09/Brazil-eyes-up-potential-for-Cachaca-inglobal-markets $>$ Acesso em 10 de abril de 2021.

Cachaça artesanal: a genuína bebida nacional. 2016. Disponível em: $<$ https://alavoura.com.br/colunas/indicacao-geografica/cachaca-artesanal-a-genuina-bebidanacional/> Acesso em : 24 de outubro de 2020. 
FIGUEIREDO, R. Finalmente, EUA assume que a cachaça é brasileira! 2013. Disponível em: $<$ https://www.mapadacachaca.com.br/noticias/finalmente-eua-assume-que-a-cachaca-ebrasileira/> Acesso em: 13 de abril de 2021.

IBRAC. Mercado interno. Disponível em: $<$ https://ibrac.net/servicos/mercado-interno> Acesso em: 06 de março de 2021.

IBRAC. Taste Brasil: O projeto. Disponível em: $<$ https://ibrac.net/taste-brasil $>$ Acesso em 10 de abril de 2021.

IMME, A. Tudo sobre análise SWOT: o que é, como fazer e muito mais!.2019. Disponível em: < https://resultadosdigitais.com.br/blog/analise-swot/> Acesso em: 01 de abril de 2021.

MEDINA, J. Cana-de-açúcar: a cultura que potencializou o Brasil!. Disponível em: < https://agropos.com.br/cana-de-acucar/> Acesso em: 15 de abril de 2021.

O Brasil no mercado mundial de bebidas alcoólicas. 2020. Disponível em: $<$ https://www.domaniconsultoria.com/post/o-brasil-no-mercado-mundial-de-bebidasalco $\%$ C3\%B3licas> Acesso em: 15 de maio de 2021.

$\mathbf{O}$ crescimento do mercado de cachaças e as perspectivas futuras. 2013. Disponível em < https://www.bebidaexpressblog.com.br/cachacas/o-crescimento-do-mercado-de-cachacas-eas-perspectivas-futuras $>$ Acesso em: 06 de outubro de 2020.

Por que os alemães gostam tanto de cachaça. 2013. Disponível em:

$<$ http://www.bebidaexpressblog.com.br/cachacas/por-que-os-alemaes-gostam-tanto-decachaca> Acesso em: 10 de janeiro de 2021.

SALATI, P. Exportação brasileira de cachaça cai $24 \%$ em 2020 com pandemia. 2021. Disponível em:

$<$ https:/g1.globo.com/economia/agronegocios/noticia/2021/01/21/exportacao-brasileira-decachaca-cai-24percent-em-2020-com-pandemia.ghtml> Acesso em: 10 de abril de 2021

SAKAI, H. R.; Árvore do conhecimento cana-de-açúcar. 2007. Disponível em: $<$ https://www.agencia.cnptia.embrapa.br/gestor/cana-deacucar/arvore/CONT000fiog1 lob502wyiv80z4s473agi63ul.html> Acesso em: 04 de outubro de 2020.

SEBRAE. Saiba mais sobre tendência do mercado de cachaça. 2017. Disponível em: $<$ https://www.sebrae.com.br/sites/PortalSebrae/artigos/saiba-mais-sobre-tendencia-domercado-de-cachaca,39aa6a2bd9ded410VgnVCM1000003b74010aRCRD $>$ Acesso em: 10 de janeiro de 2021.

SEBRAE. Como realizar a pesquisa de fornecedores e fechar parcerias confiáveis. 2014. Disponível em: $<$ https:/www.sebrae.com.br/sites/PortalSebrae/artigos/pesquisa-defornecedores,ea7836627a963410VgnVCM1000003b74010aRCRD > Acesso em: 15 de maio de 2021. 
SILVA, M. J., A história da cachaça. 2016. Disponível em:

$<$ https://engenhosaopaulo.com.br/wp-content/themes/engenhosp/anexos/historia-da-cachacaengenho-sao-paulo.pdf $>$ Acesso em 24 de outubro de 2020.

Vantagem competitiva: o que é, qual é a importância e como reforça-la. 2017. Disponível em: $<$ https://blog.egestor.com.br/o-que-e-vantagem-

competitiva/\#: : :text=Segundo\%20Porter\%2C\%20vantagem\%20competitiva\%20pode,ou\%20 aplicados\%20a\%20outros\%20neg\%C3\%B3cios.> Acesso em: 10 de março de 2021. 